\title{
Ampullary Localization of Unruptured Ectopic Pregnancy of Eighteen Weeks about a Case
}

\author{
Ajbabdi M*, Benjelloun A, Jalal M, Benjelloun AT, Oubid A, Qasseh REI, Fechtali K, Benhessou M and \\ Bouhya S
}

Obstetrics Gynecology Service, Maternity El Harrouchi, Chu Ibn Rochd, Casa, Morocco

*Corresponding author: Ajbabdi M, Obstetrics Gynecology Service, Maternity El Harrouchi, Chu Ibn Rochd, Casa, Morocco, Tel: +212771332164, E-mail: docteurajbabdimouna@gmail.com

Citation: Ajbabdi M, Benjelloun A, Jalal M, Benjelloun AT, Oubid A, et al. (2019) Ampullary Localization of Unruptured Ectopic Pregnancy of Eighteen Weeks about a Case. J Case Rep Stud 7(1): 107. doi:

$10.15744 / 2348-9820.7 .107$

Received Date: June 11, 2018 Accepted Date: February 26, 2019 Published Date: February 28, 2019

\begin{abstract}
Ectopic pregnancy is therefore implanted out of the normal implantation site of the uterine cavity. It is a surgical emergency that can compromise the vital prognosis and fertility of patients when the diagnosis is made at the stage of rupturing. Its incidence has doubled or even tripled in the world in the last two decades. Although it still remains the leading cause of maternal mortality in the first trimester by tubal rupturing accounting for $13 \%$ of maternal deaths this increase is closely linked to several factors such as sexually transmitted infections, history of salpingitis, tubal surgery, abortions, inert or progesterone associated IUD use and smoking. Tubal location is by far the most common ( 96 to $99 \%$ of cases). The clinical signs are therefore relatively late and the rupture of the tube is preceded by a fissure syndrome. We report a rare case of unruptured ampullary pregnancy that has evolved to 18 weeks.
\end{abstract}

Keywords: Ectopic; Advanced Pregnancy; Amplular Localization

\section{Introduction}

Ectopic pregnancy or extrauterine pregnancy is defined as implantation and subsequent development of the zygote at a site other than normal intrauterine cavity [1]. It is a surgical emergency that can compromise the vital prognosis and fertility of patients when the diagnosis is made at the stage of breaking. Although it still remains the leading cause of maternal mortality in the first trimester by tubal breaking accounting for $13 \%$ of maternal deaths this increase is closely linked to several factors such as sexually transmitted infections, history of salpingitis, tubal surgery, abortions, IUD use and smoking [2-4]. Tubal location is by far the most common (96 to $99 \%$ of cases). The whole fallopian tube may be interested. The bulb, especially the isthmo-ampullary junction is the preferred location anatomically, this segment is wide and extensible [5]. Ultrasonography and serial estimates of serum human chorionic gonadotropin (hCG) are used to detect or rule out ectopic pregnancy in women with vaginal bleeding or abdominal pain with delay of menstruation [6].

The clinical diagnosis of USG but is not always easy to find [7]. The clinical signs are therefore relatively late and the rupture of the tube is preceded by a fissure syndrome. We report a rare case of unruptured ampullary pregnancy that has evolved to 18 weeks.

\section{Case Presentation}

Mrs K, 27 years old, mother of a living child (vaginal delivery for a pregnancy completed 6 years ago), the history of the disease began with 18 weeks of late menstruation associated with metrorrhagia of average abundance and pelvic pain. She had no risk factors for ectopic pregnancy. On examination, the patient was 15/15 conscious, hemodynamically and respiratory stable. The abdominal examination revealed slight pelvic area sensitivity associated with a left iliac mass of about $20 \mathrm{~cm}$. Bimanual pelvic examination revealed a left lateral uterine mass approximately $18 \times 20 \mathrm{~cm}$, felt separately from the uterus with reduced mobility.

\section{At Para clinical Investigations}

The initial hemoglobin was $11.8 \mathrm{~g} / \mathrm{dl}$. The quantitative beta-hCG: $76000 \mathrm{miu} / \mathrm{ml}$. The ultrasound revealed a left gestational sac with an 18-week gestational age fetus without fetal cardiac activity and showed an enlarged uterus with an empty uterine cavity. Both Ovaries were normal (Figure 1). The patient was taken for emergency laparotomy after duly obtaining informed consent. Laparotomy revealed a left infundibula tubal pregnancy measuring approximately $18 \mathrm{~cm}$ long, so a left salpingectomy 

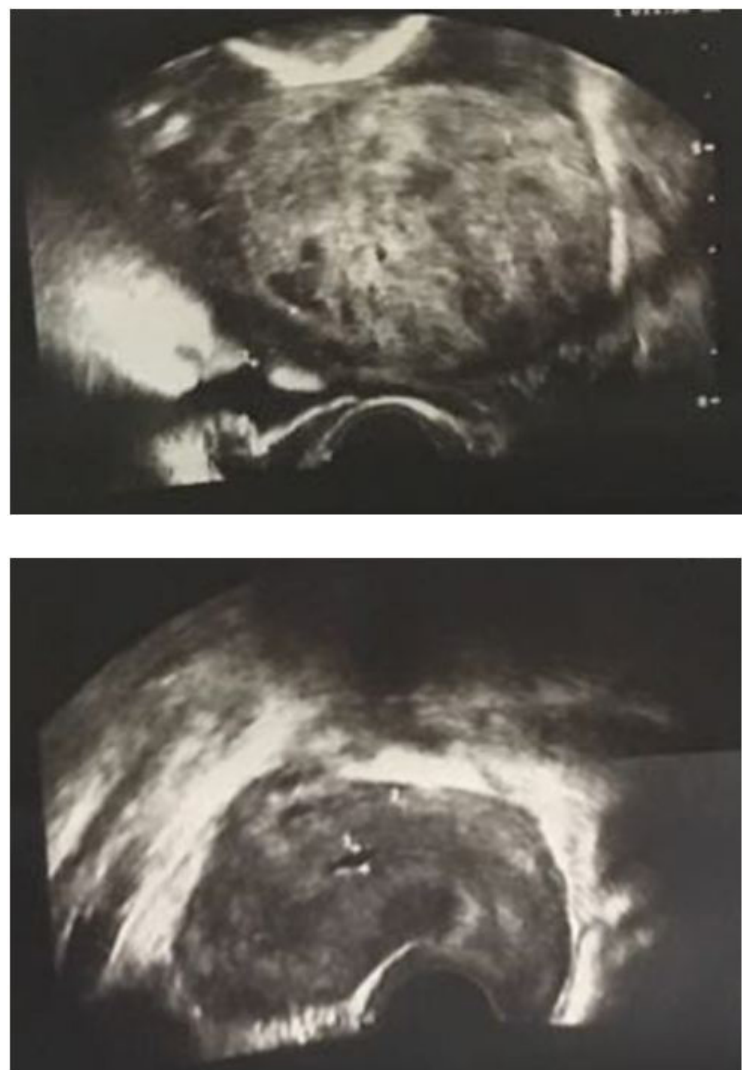

Figure 1: Echographic image of ectopic pregnancy 18 week of amenorhea

was performed. On exploration: the right fallopian tube and the ovary were normal (Figure 2). The histological examination of the piece showed a fallopian tube with ectopic gestation in the fetus corresponding approximately to 18 weeks of gestation. The patient's post-operative course was uneventful.
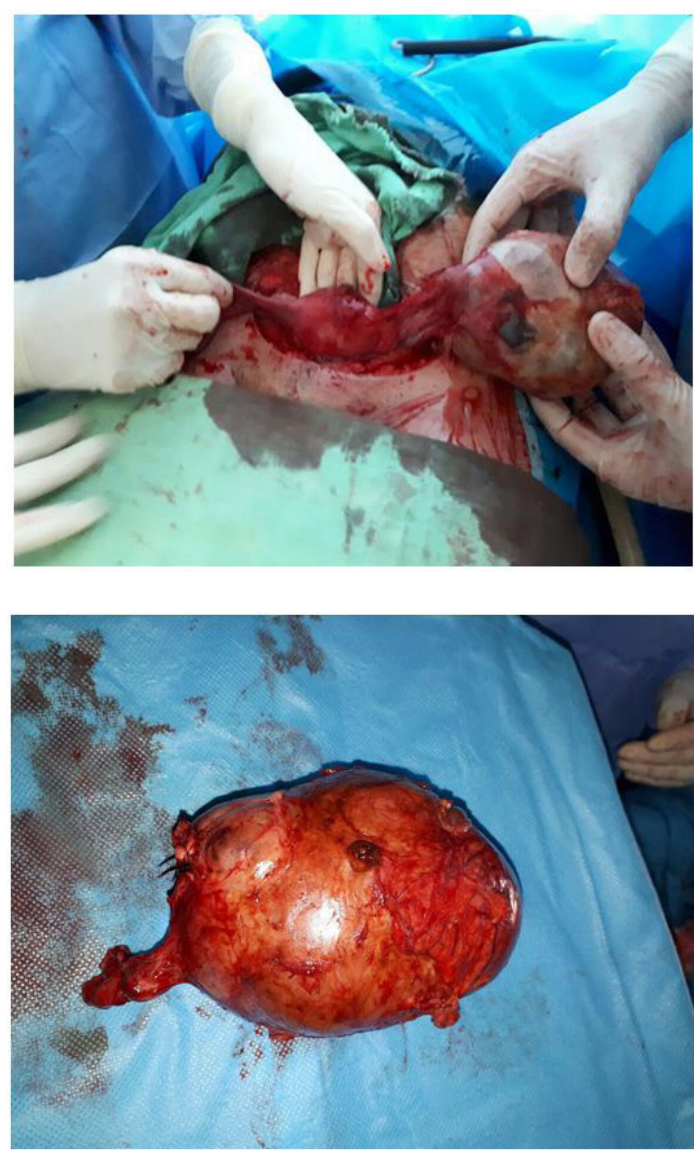


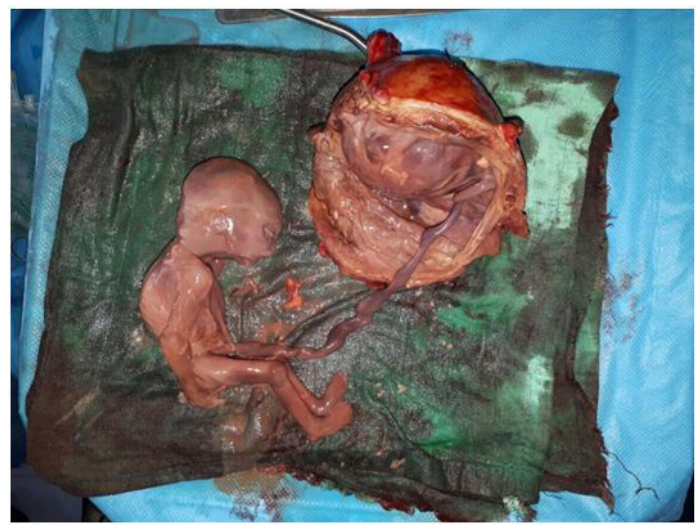

Figure 2: Image of the operative part

\section{Discussion}

Advanced Ampullary localization of ectopic pregnancy is rare. the doubling time of serum beta-hcg and the transvaginal ultrasound make it possible to identify precocious ectopic pregnancy. the absence of transvaginal ultrasound in the first trimester leads to the late diagnosis of ectopic pregnancy. However, despite transvaginal ultrasound performed during the first trimester, an ectopic pregnancy may be missed because of inexperienced radiologists or the presence of a heterotopic pregnancy Mert Gol et al. reported a case of ectopic tubal rupture of 17 weeks [8]. One case of late ectopic pregnancy was reported in a 1989 publication: it is an ampullary pregnancy whose diagnosis was established only at laparotomy [9]. More recently, R.Mhaskar published a case of right-sided ampullary ectopic pregnancy conducted up to 16 weeks with a live fetus treated with salpingectomy [8]. We believe that transvaginal ultrasound by a radiologist Experiment with a first-trimester serum beta-HCG doubling time is the best diagnostic modality for the early diagnosis of ectopic pregnancy [8].

\section{Conclusion}

Ectopic pregnancy is defined as the implantation of a pregnancy outside the uterus. This definition excludes interstitial, cervical and cornual pregnancies. It is a surgical emergency that can compromise the vital prognosis and fertility of patients when the diagnosis is made at the stage of breaking. All segments of the trunk may be interested. The bulb, especially the isthmo-ampullary junction is the preferred location anatomically, this segment is wide and extensible. Ultrasonography and serial estimates of serum human chorionic gonadotropin (hCG) are used to detect or rule out ectopic pregnancy in women with vaginal bleeding or abdominal pain with rule delay. The presence of a lateral, uterine, sensitive, poorly limited mass is an important element in the diagnosis of the USG but is not always easy to find, while the painful wheelbase of the cul de sac is often present. The clinical signs are the refore relatively late and the rupture of the tube is preceded by a fissure syndrome. We report a rare case of unruptured ampullary pregnancy that has evolved to 18 weeks.

\section{References}

1. Walker JJ (2007) Ectopic pregnancy. Clin Obstet Gynecol 50: 89-99.

2. Barnhart K, Esposito M, Coutifaris C (2000) An update on the medical treatment of ectopic pregnancy. Obstet Gynecol Clin North Am 27: 653-67.

3. Monnier JC, Vantyghena A, Antyghen H, Lauciaub A, Haudiquetm C (1999) Ectopic pregnancy: epidemiological, diagnostic, therapeutic and prognostic aspects. About 117 observations. J Gynaecol Obstet Biol Reprod 14: 67-75.

4. Mouelhi C, Akremi A, Bouaziz M, Zhioua F, Mitou I (2003) Coeliosurgical treatment of the USG about 74 cases. Medical Maghreb $2003: 321$.

5. Senterman M, Jibodh R, Tulandi T (1988) Histopathologic study of ampullary and isthmic tubal ectopic pregnancy. Am J Obstet Gynecol 159: 939-41.

6. Surampudi K, Gundabattula SR (2016) The Role of Serum Beta hCG in Early Diagnosis and Management Strategy of Ectopic Pregnancy. J Clin Diagn Res 10: QC8-10.

7. Dupuis O, Camaga O, Benifla J, Batllan A, Dhainaut R, Renolleau C, et al. (2006) Ectopic pregnancy. Obstet Gynecol 10.1016/S0246-0335(09)52463-5.

8. Mhaskar R, Harish M, Jaiprakash T (2014) Unruptured Ampullary Ectopic Pregnancy at 16-week Period of Gestation with Live Fetus. J Obstet Gynaecol India 64: 73-4.

9. Glew SS, Sivanesaratnam V (1989) Advanced extrauterine mimicking intrauterine fetal death: case reports. Aust NZJ Obstet Gynaecol 29: 450-1. 


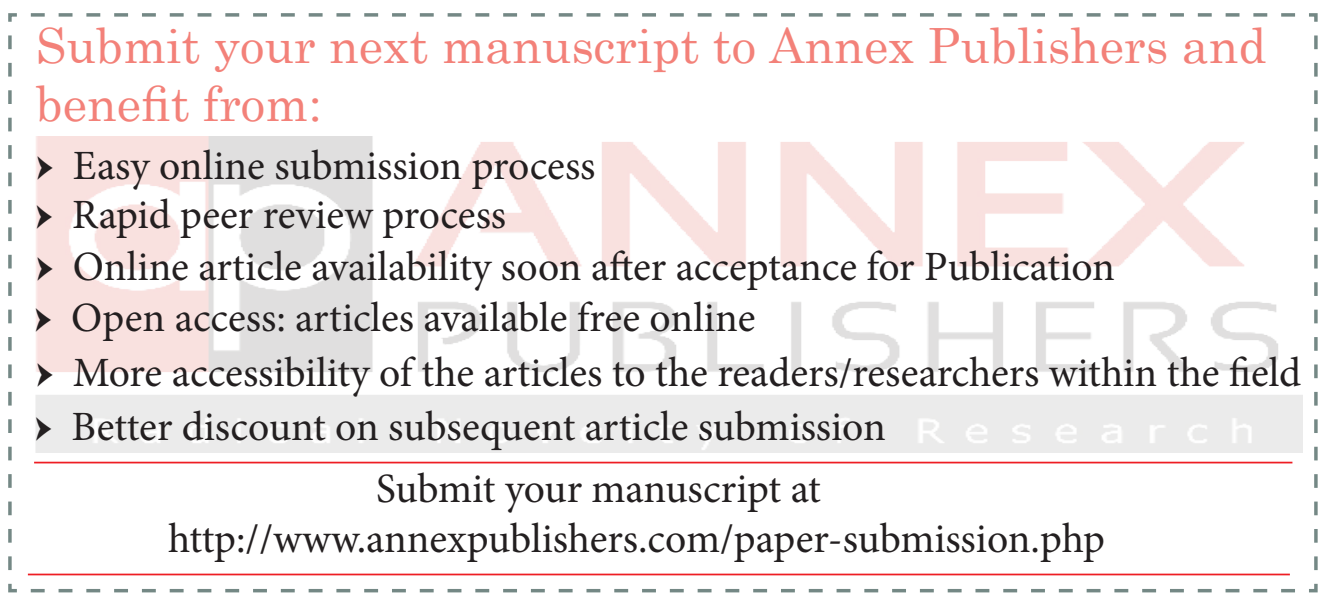

